\title{
Double Compression Expansion Engine: A Parametric Study on a High-Efficiency Engine Concept
}

\author{
Author, co-author (Do NOT enter this information. It will be pulled from participant tab in \\ MyTechZone) \\ Affiliation (Do NOT enter this information. It will be pulled from participant tab in MyTechZone)
}

\begin{abstract}
The Double compression expansion engine (DCEE) concept has exhibited a potential for achieving high brake thermal efficiencies (BTE). The effect of different engine components on system efficiency was evaluated in this work using GT Power simulations. A parametric study on piston insulation, convection heat transfer multiplier, expander head insulation, insulation of connecting pipes, ports and tanks, and the expander intake valve lift profiles was conducted to understand the critical parameters that affected engine efficiency. The simulations were constrained to a constant peak cylinder pressure of 300 bar, and a fixed combustion phasing. The results from this study would be useful in making technology choices that will help realise the potential of this engine concept.
\end{abstract}

\section{Introduction}

The quest for improving the efficiency of the internal combustion (IC) engine has never seemed more critical. Even while the oil prices have been low for the last few years, the increasing pressure to curb $\mathrm{CO}_{2}$ emissions has meant that the drive to increase energy conversion efficiency will be sustained over the coming decades. The rise of electric powertrains has created a healthy competition for the IC engine. Improving the efficiency of the IC engine is vital for its sustained existence. The SuperTruck program was a successful partnership between Department of Energy (DoE) and industry in creating a research program that resulted in achieving 50\% Brake Thermal Efficiency (BTE) from the engine at road load as well as defining pathways to attain 55\% BTE [1]. The double compression expansion engine (DCEE) is a new engine architecture that could achieve the very high target efficiency set by the SuperTruck program $[2,3]$. The design provides a reduced surface area to volume ratio during combustion which reduces heat transfer losses. The combustion gases are over-expanded in the large low-pressure unit to minimise exhaust losses. The friction loss is also minimised [2]. The concept is a highly down-sized engine with a highly efficient charging system (piston compressor-expander unit). The present work expands on the concept by introducing a different architecture and then conducting a parametric study on various system components to understand their effect on the efficiency of the engine. This study aims to provide an understanding of the most critical components of the system, highlight the engineering challenges that lie in achieving 55\% BTE and assist in making the technological choices that would provide the most significant benefits.

Page 1 of 9

\section{Double Compression Expansion Engine}

An embodiment of a two-stage compression and expansion engine with a large low-pressure compression-expansion unit and a smaller high-pressure compression-combustion-expansion unit was introduced by Nhut et al. [2]. The engine was simulated and compared to a single stage engine with the same effective compression ratio using GT Power. The simulations revealed that the concept had a high potential for achieving 55\% BTE. The marked improvement in efficiency over the single stage engine was attributed to a reduced heat transfer loss as a result of a lower surface area to volume ratio during the heat addition process, and a smaller exhaust loss due to overexpansion in the large low-pressure unit. The sensitivity of the DCEE's efficiency to the nature of heat release during the combustion process was stimulated by the authors of this work in Ref.[3]. The concept exhibited a low sensitivity of its efficiency to different heat release rates when the peak cylinder pressure was kept constant and if the low-pressure unit was adapted accordingly. The simulations used a fixed convection heat transfer multiplier (CHM) which limited the conclusions drawn from the study. However, the study showed that a slower combustion process could be accommodated within the concept if it reduced the heat transfer loss as a well-adapted low-pressure unit would over-expand the higher energy combustion gases thus maintaining low exhaust losses even for a slower rate of heat release. Increasing the expansion ratio to minimise exhaust losses for a slower heat release rate would either result in an increased compression ratio or miller timing in single stage engine. The former would increase surface area to volume ratio, and the latter would decrease the power density of the engine. The DCEE concept affords an extra degree of freedom to design combustion processes that would minimise heat transfer losses without increasing exhaust losses. The benefit of reduced heat loss with greater effective expansion ratio has been demonstrated only in low-temperature combustion (LTC) concepts such as Partially Pre-mixed Compression Ignition (PPCI) or Reactivity Controlled Compression Ignition (RCCI). The heat flux to the walls has been shown to decrease with retarded combustion in LTC engines as well [4], and hence a DCEE with LTC would be very beneficial. The low-temperature combustion concepts have been successfully demonstrated in labs and demonstration vehicles but lack the required controls has stopped to their adoption in production vehicles. Recently Mazda has introduced the Skyactiv X that works has LTC at part load operation.

This work presents a different embodiment of a staged piston reciprocating internal combustion engine. The low-pressure compression-expansion unit is decoupled into two separate units, one 
for the $1^{\text {st }}$ stage compression, and another for overexpansion. The units are connected to two high-pressure units (Combustors) through wellinsulated pipes, runners, and large tanks. Figure 1 provides a schematic of the new configuration. The inlet air is compressed in the compressor unit, and transferred to and stored in a large insulated volume (20 liters) (Event 1). This volume will be referred to as 'Cold Tank'. The compressed air is then inducted into the Combustor (Event 2) where it is compressed again followed by heat addition through combustion, and expanded. The high pressure-high temperature exhaust from the combustion unit is exhausted into another large volume ('Hot Tank') (Event 3). The intake and exhaust gas transfer processes are meant to occur at nearly constant pressure due to the presence of these tanks. Their implementation reduces to flow losses that result from uncontrolled expansion and avoids dead volumes in the pipes. The gases are then further expanded in a separate lowpressure unit ('Expander'). The compressor and expander units act on 2-stroke principle while the high-pressure units operate on a 4-stroke cycle. The system uses poppet valves on all cylinders. Figure 2 exhibits the various cylinder and tank pressures along with indications for the gas exchange events. Table 1 contains the sizing of different cylinders.

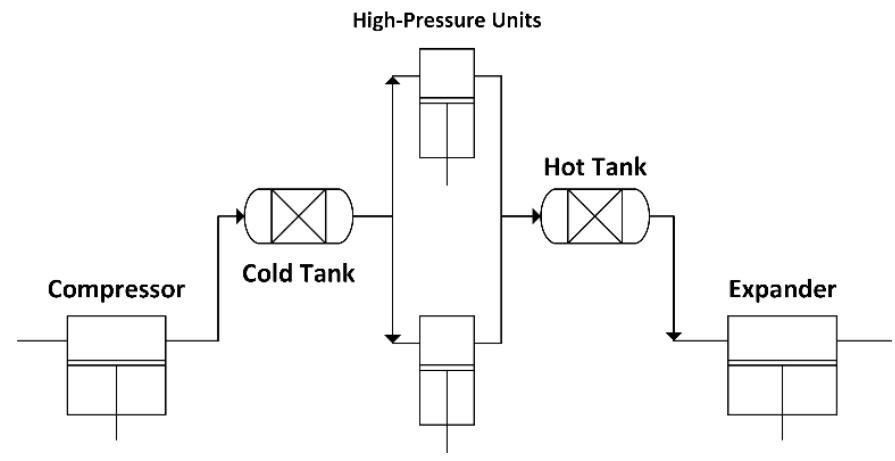

Figure 1. Schematic of the Double Compression Expansion Engine Concept

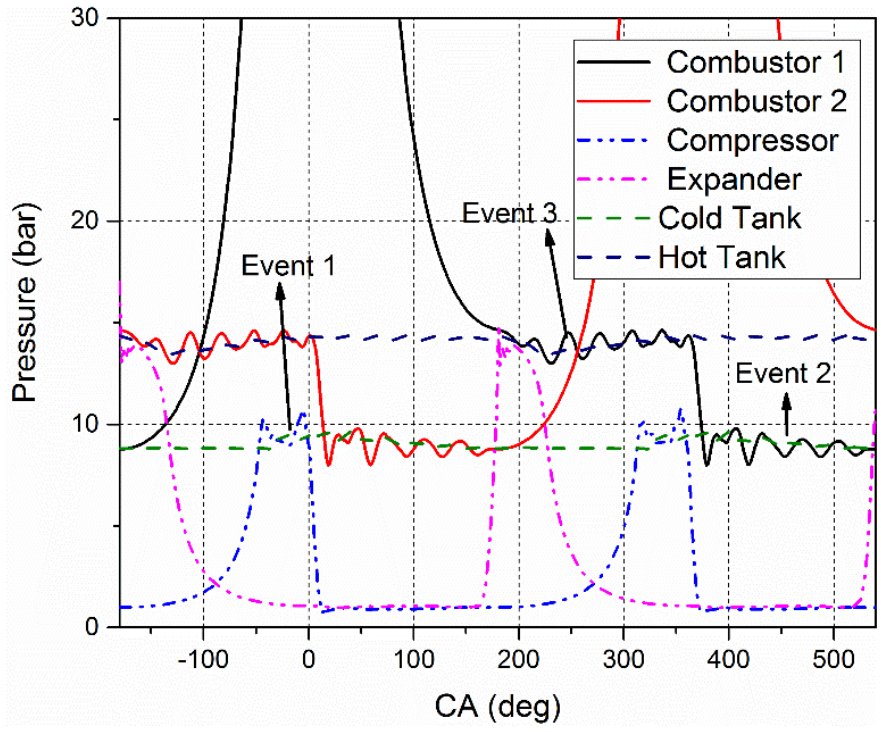

Figure 2. Pressures in different DCEE system components. Events 1, 2, and 3 are the different gas exchange events.

The back pressure in the high-pressure cylinder units is very high, and hence a higher compression ratio is chosen to reduce the quantity of exhaust gas trapped in the clearance volume. The filling of the expander unit determined by the expander intake valve timing Page 2 of 9 determines the hot tank pressure and hence the back pressure acting on the combustion cylinders.

Table 1. High-Pressure Unit, Compressor, and Expander dimensions

\begin{tabular}{|c|c|c|c|}
\hline & $\begin{array}{c}\text { High-Pressure } \\
\text { Unit }\end{array}$ & Compressor & Expander \\
\hline Bore (mm) & 131 & 284.9 & 340 \\
\hline Stroke & 120 & 120 & 120 \\
\hline $\begin{array}{c}\text { Con-rod } \\
\text { length (mm) }\end{array}$ & 180 & 180 & 180 \\
\hline $\begin{array}{c}\text { Compression } \\
\text { Ratio }\end{array}$ & 11.5 & 194 & 194 \\
\hline
\end{tabular}

\section{Modelling Approach}

The DCEE concept was modelled using GT Power. The program solves 1-D Navier-Stokes equations with specified boundary conditions to compute the fluid flow in pipes, and inside the cylinders. The combustion cylinders have built-in combustion, heat transfer, and wall-temperature models. The simulations used the DI Wiebe combustion model. The model was tuned to achieve a peak cylinder pressure of $300 \mathrm{bar}$, and a CA 50 of $6^{\circ}$ after top dead centre (ATDC). $-7^{\circ}$, and $-4^{\circ}$ ATDC were the start of injection, and combustion events, respectively. A WoschiniGT heat transfer model was used for solving the heat transfer inside the cylinder units. The head to bore area ratio and piston to bore area ratio were fixed at 1 and 1.2, respectively. The convection heat transfer multiplier (CHM) was varied in the study, while the radiative heat transfer was pegged at 1 . The wall-temperature model uses finite element representation to solve and predict the temperatures of the cylinder liner, piston, head, and valves. The geometries of runners, manifolds, and ports were conceived for minimising heat loss. It is composed of fibre insulation with $10 \mathrm{~mm}$ thickness surrounded by $4 \mathrm{~mm}$ outer layer made of iron. The ports were surrounded by coolant fixed to a temperature of $389 \mathrm{~K}$. The thermal conductivity of the fibre insulation material is shown in table 2 . The cold and hot tanks were modelled as large pipes with a volume of 20 L. Their walls were also made of $25 \mathrm{~mm}$ fibre insulating material, and $5 \mathrm{~mm}$ thick iron layer on the outside. The hot tank was assumed to be inside the cold tank, and therefore its heat transfer was accordingly evaluated based on the fluid conditions inside the cold tank. The heat rejected from the hot tank was not recuperated in the cold tank. The expander piston was considered to be well insulated, and its thermal conductivity was $0.9 \mathrm{~W} / \mathrm{m}-\mathrm{K}$ in the simulations. The assumption of such a high level of insulation of the runners, manifolds, ports, tanks, and expander piston in the model was based on internal studies [5], and assessments.

The valve timings and coefficient of discharge (Cd) of a Volvo MD13 engine were adopted for the high-pressure units. The valve timing on the compressor was adjusted to attain the required compression pressure. The Cd from Volvo MD-13 engine was also used for the valves on the compressor and expander units. The results in the present work are discussed in terms of indicated thermal efficiency (ITE) as 
the peak pressure in all the cases simulated were very similar, and hence the mechanical efficiency was considered to be constant.

Table 2. Thermal Conductivity of Fiber Insulation

\begin{tabular}{|c|c|}
\hline Temperature (K) & Thermal Conductivity (W/m-K) \\
\hline 300 & 0.05 \\
\hline 873 & 0.11 \\
\hline 1073 & 0.14 \\
\hline 1273 & 0.19 \\
\hline
\end{tabular}

\section{Results and Discussion}

\section{High-Pressure Unit Piston Insulation and Convection Heat Multiplier}

The benefits of piston insulation for the DCEE concept was studied by changing the piston thermal conductivity (PTC) from $48 \mathrm{~W} / \mathrm{m}-\mathrm{K}$ which corresponds to a heavy-duty carbon steel piston to $1 \mathrm{~W} / \mathrm{m}-\mathrm{k}$, which is close to an adiabatic piston, at varying intervals. Low heat rejection materials have been investigated in the service of reducing the cylinder heat transfer loss by several researchers, and a good summary of literature is provided by Jaichander and Tamilporai[6]. They report based on their survey that adding low heat rejection materials to the combustion cylinder usually leads to an increase of fuel consumption in naturally aspirated engines by about $0-10 \%$, and a reduction of fuel consumption by a similar amount for turbocharged, and $10-15 \%$ in turbo-compound engines[6]. The deterioration in engine efficiency when applying insulation has been attributed to increased heat transfer coefficient due to fuel burning closer to the walls as hypothesized by Woshini et al.[7] and a slower combustion rate. The slower combustion rate was ascribed to the reduction in ignition delay time as a result of higher cylinder temperatures which reduced the amount of pre-mixed combustion and lowered volumetric efficiency[8]. The considerably larger gas viscosity also contributed to diminished mixing rate further retarding the heat release rate[9]. The reduced volumetric efficiency is countered by turbochargers which receive greater heat energy from the combustion cylinders which facilitates increased inlet pressures. The present simulations were conducted assuming a constant combustion phasing, and at a fixed convection heat transfer multipliers, hence many of the mechanisms through which insulation reduces efficiency as reported in the literature were not considered. Therefore, the present simulations were not expected to reveal any reduction in efficiency.

The simulations also evaluated the effect of insulation for different convection heat transfer multipliers (CHM). Figure 3 presents the results of the simulation. Figure 4 exhibits the energy loss inside and after high-pressure cylinders.

The effect of the CHM is much more pronounced than reducing the PTC. The reduction in cylinder heat loss as PTC is changed from 48 $\mathrm{W} / \mathrm{m}-\mathrm{K}$ to $1 \mathrm{~W} / \mathrm{m}-\mathrm{K}$ is $8 \mathrm{~kW}$ ( $5 \%$ of the fuel energy) with an increase of $4 \mathrm{~kW}$ in heat transfer and exhaust losses after the combustion cylinders. The challenges in designing an adiabatic piston are immense. However, Uchida and Osada[10] have demonstrated an insulated piston concept that reduced heat loss by $1.5-2.5 \%$ of the fuel energy by coating Zirconia on the backside of a piston to elevate the surface temperature without compromising mechanical efficiency. The proposed piston insulation did not lead to combustion deterioration as the piston surface on the combustion side was not modified. The improvement in heat loss reduction in Ref.[10] corresponds to a piston with a thermal conductivity of $10 \mathrm{~W} / \mathrm{m}-\mathrm{K}$ in the simulations. The reduction in CHM from 1 to 0.5 with a $48 \mathrm{~W} / \mathrm{m}-\mathrm{K}$ PTC results in the reduction of cylinder heat transfer losses by $12 \mathrm{~kW}(\approx 7.5 \%$ of fuel energy). The reduction is in line with the observations of Turner et al.[11], and Chuahy and Kokjohn [12] in low-temperature combustion concepts of Partially Premixed Combustion (PPC) and Reactivity Controlled Compression Ignition (RCCI), respectively. The CHM value of 0.5 is more conservative than 0.38 used by Turner et al.[11]. The reduced surface area to volume ratio in the DCEE high-pressure unit may account for obtaining similar reductions in heat loss even with a slightly larger CHM value.

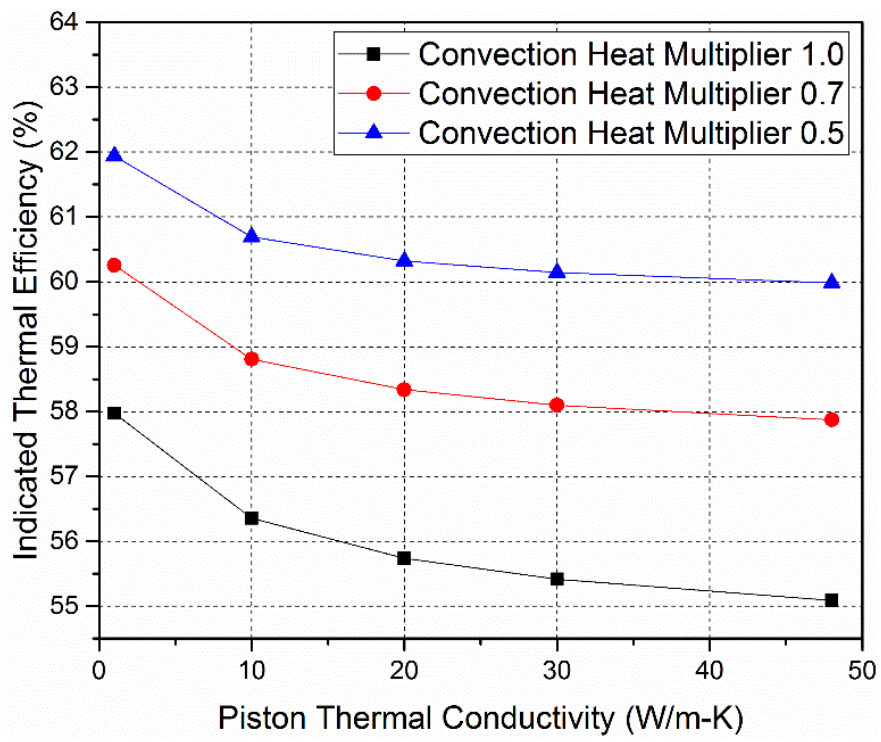

Figure 3. Parametric Sweep of Piston Thermal Conductivity and Convection Heat Multiplier in Combustion Cylinders, and their effects on ITE

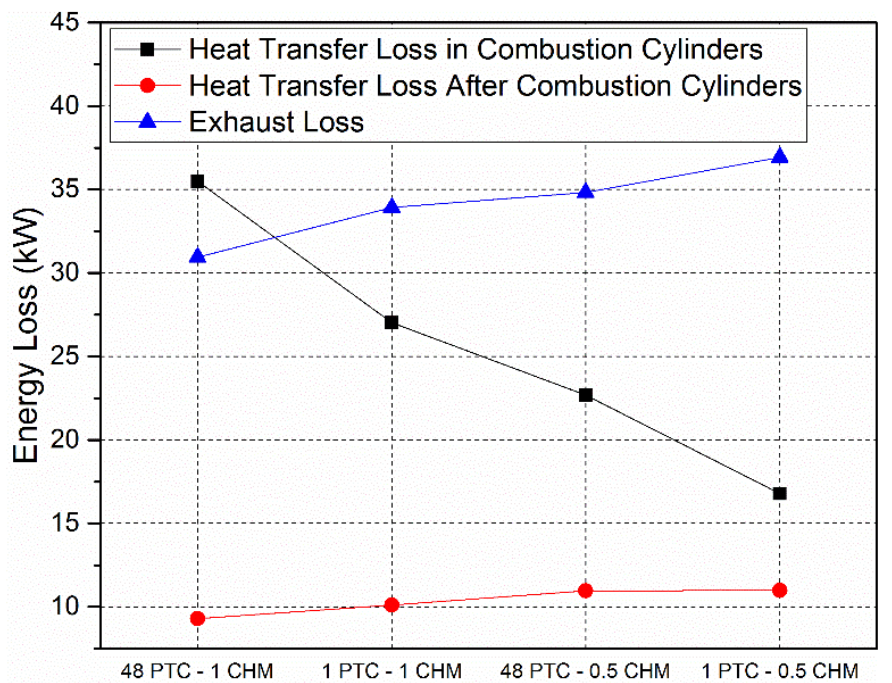

Page 3 of 9 
Figure 4 shows that the energy saved due to reduced wall heat transfer is well utilized in the DCEE concept. The heat transferred marginally increases along the piping, hot tank, and the expander with an insulated piston or reduced CHM. The use of well-insulated pipes, ports and expander piston are thus significant in keeping the heat losses to a minimum as the pressure and temperature of the gases in them are substantially higher than those encountered in other engines. The effect of varying levels of insulation of these parts will be discussed later. The large expander unit converts a considerable portion of the saved energy into piston work as a piston expander's isentropic efficiency is higher than a turbocharger.

The results indicate that finding avenues to implement lowtemperature combustion concepts which have reduced CHM in DCEE will be a crucial factor in achieving the target efficiency. However, it has been shown that diesel is not the ideal fuel for PPC combustion[13], and RCCI requires at least two fuels with different octane rating. Therefore, considerable challenges lie in the path of accomplishing low-temperature combustion with diesel fuel. The piston insulation proposed by Uchida and Osada [10] coupled to a lowtemperature combustion with $\mathrm{CHM}$ of 0.5 or below would enable the concept to achieve an indicated thermal efficiency $>60 \%$.

\section{Expander Insulation and Expander Re-sizing}

The influence of insulating the expander head was evaluated by the changing the expander head thermal conductivity (EHTC) from the baseline value of $48 \mathrm{~W} / \mathrm{m}-\mathrm{K}$ to $20 \mathrm{~W} / \mathrm{m}-\mathrm{K}$ and $1 \mathrm{~W} / \mathrm{m}-\mathrm{K}$ while sweeping the high-pressure unit's PTC while fixing its CHM to 0.5 . Figure 5 contain the results of the simulations. The heat transfer loss in the expander is reduced by $3 \mathrm{~kW}$ as the EHTC is reduced from 48 $\mathrm{W} / \mathrm{m}-\mathrm{K}$ to $1 \mathrm{~W} / \mathrm{m}-\mathrm{K} .2 \mathrm{~kW}$ of the saved heat energy is lost in the exhaust. The insulation of high-pressure units and the expander leads to reduced heat transfer losses as expected since any adverse influences of insulation on combustion were not considered in the simulations. The expander was able to convert a considerable portion of the saved energy into piston work enhancing the indicated thermal efficiency of the system. The exhaust losses however still increase, suggesting a resizing of expander might help further increase the ITE. The impact of re-sizing the expander was evaluated for the configuration with maximum reduction in heat transfer losses (CHM 0.5, 1 PTC).

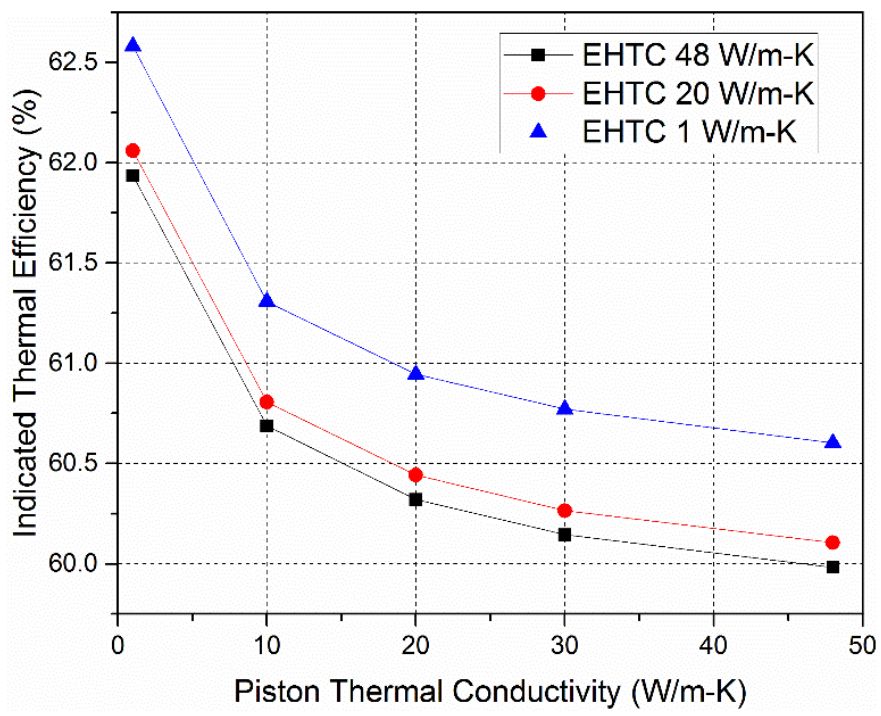

Page 4 of 9
Figure 6 shows that re-sizing the expander does not substantially increase thermal efficiency. The ITE, in fact, increases only marginally for $350 \mathrm{~mm}$ expander bore and then decreases infinitesimally when enlarged to $360 \mathrm{~mm}$. Figure 7 shows the high-pressure units heat transfer losses, expander heat transfer loss, and exhaust loss for three different expander sizes.

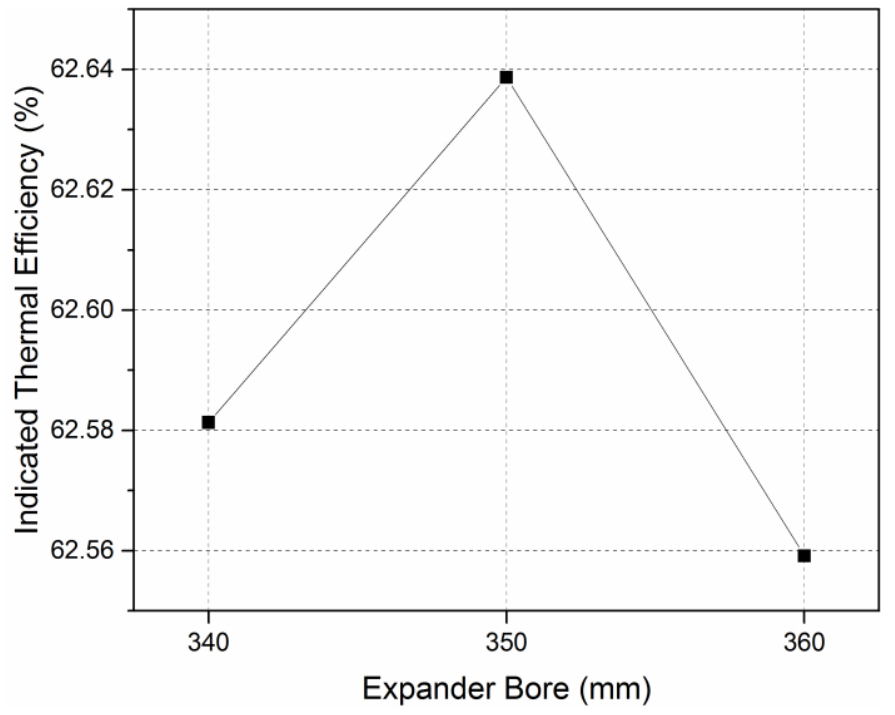

Figure 6. Indicated Thermal Efficiency with resized expander bore diameter. The re-sizing has minimal effect on ITE.

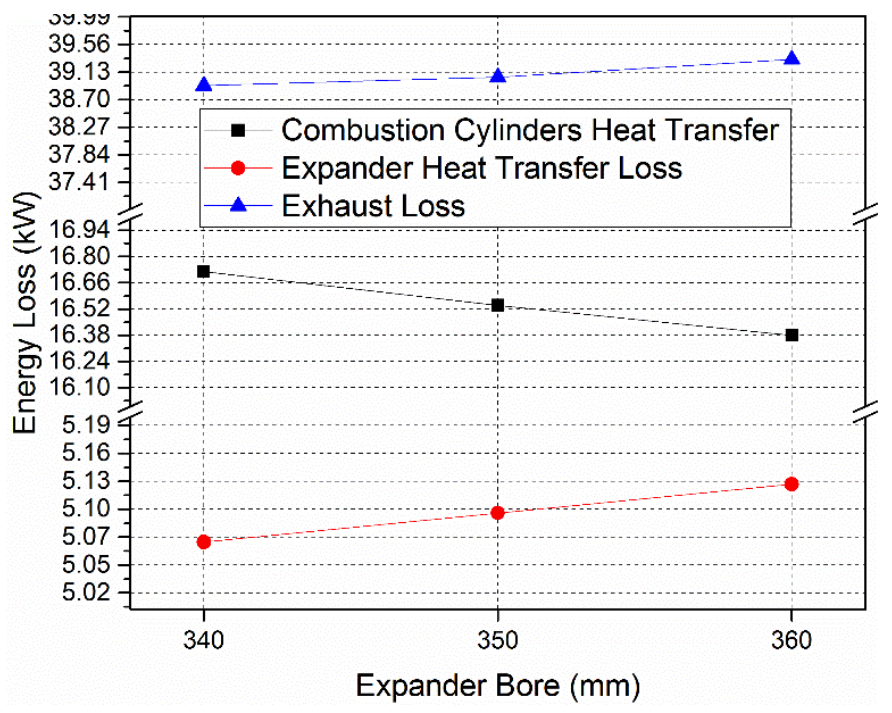

Figure 7. Energy Loss Distribution with different Expander Bore Diameters

Increasing the size of the expander contrary to expectation increases the exhaust loss as well as heat transfer loss in it. The heat transfer loss in the high-pressure units however decreases. The reason for this trend can be ascertained by observing the pressures in different system components which are shown in Figure 8. The use of a larger expander diminishes the hot tank pressure as a more significant quantity of gas is consumed by the expander for the same valve lift profile. The more substantial mass of combustion gases in the expander increases the exhaust loss while the larger surface area increases the heat transfer loss. The reduced back-pressure acting on the high-pressure units 
during the exhaust stroke diminishes the heat loss in them. The presence of a hot tank between the high-pressure units and the expander in the present configuration created a trade-off between obtaining more significant output from the expander unit with a higher inlet pressure and increased pumping and heat transfer losses in the high-pressure units. The re-sizing of the expander did not impact the efficiency as we had assumed it would, and it had in fact altered the power distribution between the high-pressure units and expander in reversal to our expectations as shown in Figure 9.

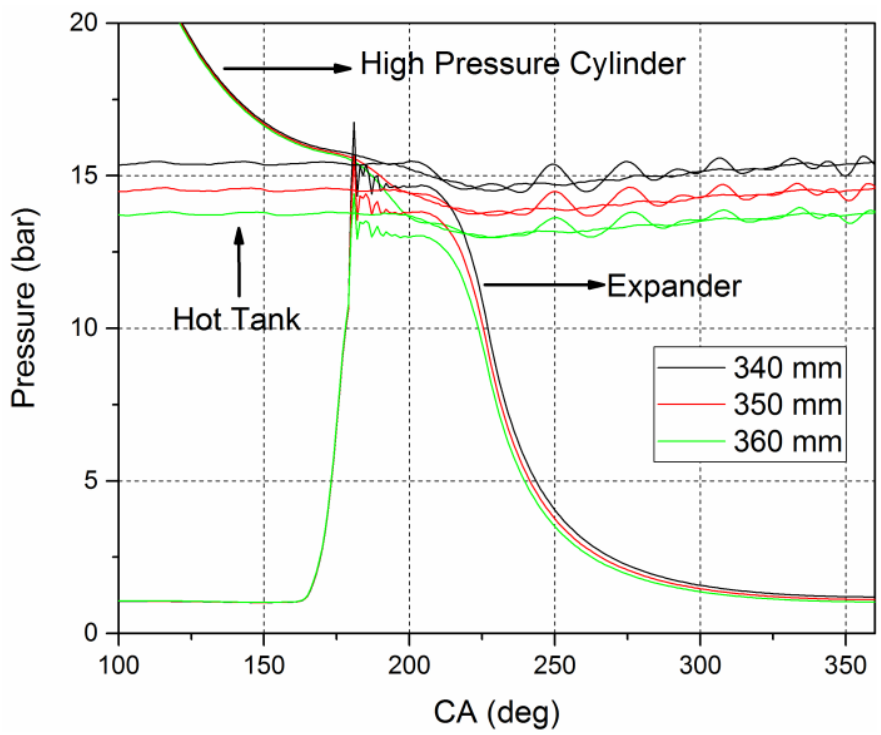

Figure 8. Pressures in High-Pressure Unit, Expander, and Hot Tank for different Expander Bore diameters. Larger expander size reduces the hot tank pressure and hence back pressure acting on the combustion cylinders.

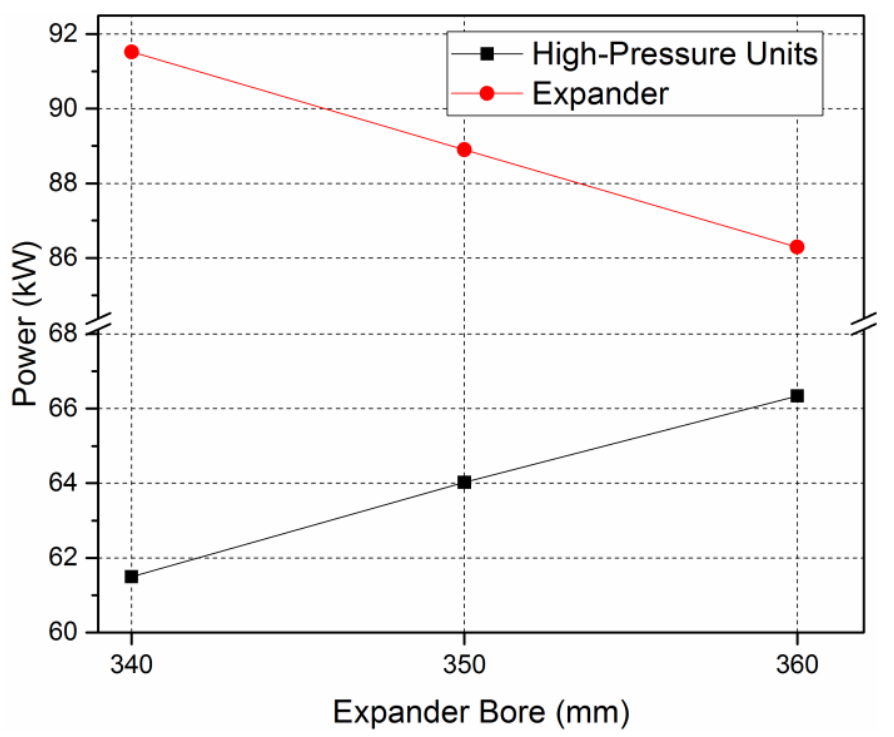

Figure 9. Power from high-pressure units and expander. The parity in the power distribution decreases with a larger expander size.

The inlet valve profile was altered for the $360 \mathrm{~mm}$ expander, and the resulting pressure profiles are plotted in Figure 10. The altered valve profile was designed to reduce the gas intake of the expander which increases the hot tank pressure. This change led to a deterioration in ITE from $62.56 \%$ to $62.23 \%$. The results indicate that the valve profile of the expander inlet has to be varied to arrive at a local optimum between these different loss pathways to achieve the best efficiency point.

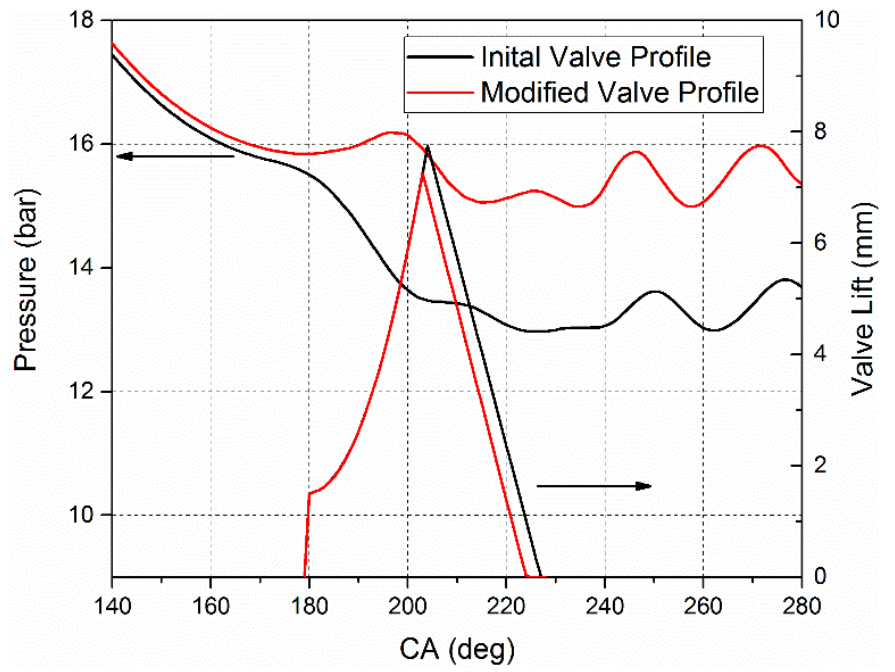

Figure 10. Effect of modifying valve lift on high-pressure unit's back pressure. The modified reduces the filling capacity of the expander increasing hot tank pressure and back pressure acting on the combustion cylinders.

\section{Effect of Runners, Manifolds, Ports, and Hot Tank Insulation Thickness}

The influence of insulation thickness in runners, manifolds, and ports on the efficiency of the DCEE concept was evaluated for a CHM of 0.5 in the high-pressure units, and two levels of insulation in the highpressure units and the expander. The piping geometry was discussed earlier in the modelling section. The thickness of the fibre insulation was changed, and the resulting ITE are plotted in Figure 11. The improvement in ITE follows an identical trend for both levels of insulation with additional insulation thickness. The ITE in enhanced by $1 \%$ point when upgrading the insulation thickness to $5 \mathrm{~mm}$ from $1 \mathrm{~mm}$, and supplementing the insulation further results in marginal gains of ITE. The heat transfer along the pipes indicated power, and exhaust loss as a function of insulation thickness are summarized in Figure 12 for high-pressure units with $0.5 \mathrm{CHM}, 20 \mathrm{~W} / \mathrm{m}-\mathrm{K}$ PTC, and EHTC of $20 \mathrm{~W} / \mathrm{m}-\mathrm{K}$. The conversion efficiency of the energy saved through insulation is around $30 \%$ with the remaining exiting through the exhaust.

The hot tank insulation thickness was varied, and three different system configurations were considered - the hot tank inside the cold tank without heat recuperation, the hot tank outside the cold tank, and the hot tank inside the cold tank with heat recuperation. The recuperation was modelled by an initial run that computed the heat loss from the hot tank, and this heat energy was added to the cold tank. The results converged after few iterations. The results presented Figure 13 suggest that recuperating energy from the hot tank in the cold tank leads to a minimal effect on ITE with reductions in insulation thickness. The corollary is also true that for a more significant insulation thickness of the hot tank its placement does not have any impact on ITE. This result provides greater flexibility in the design and packaging of the engine. The cost and design challenges of placing the

Page 5 of 9 
hot tank inside the cold tank need to be evaluated against implementing increased insulation thickness.

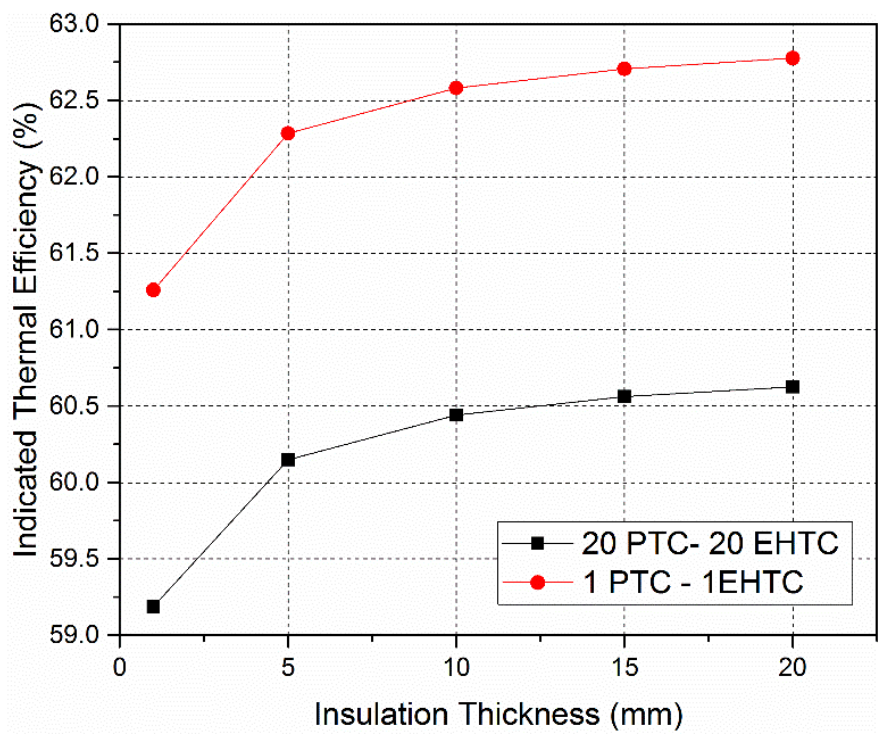

Figure 11. Increasing ITE with additional insulation thickness

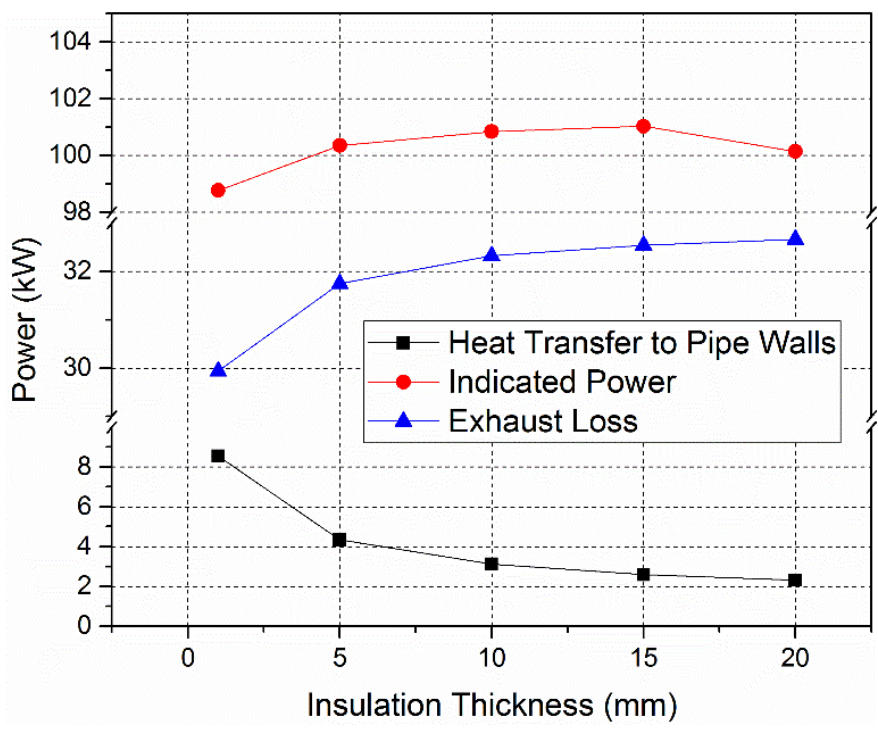

Figure12. Reduction in pipe heat transfer loss and corresponding increase in indicated power and exhaust loss

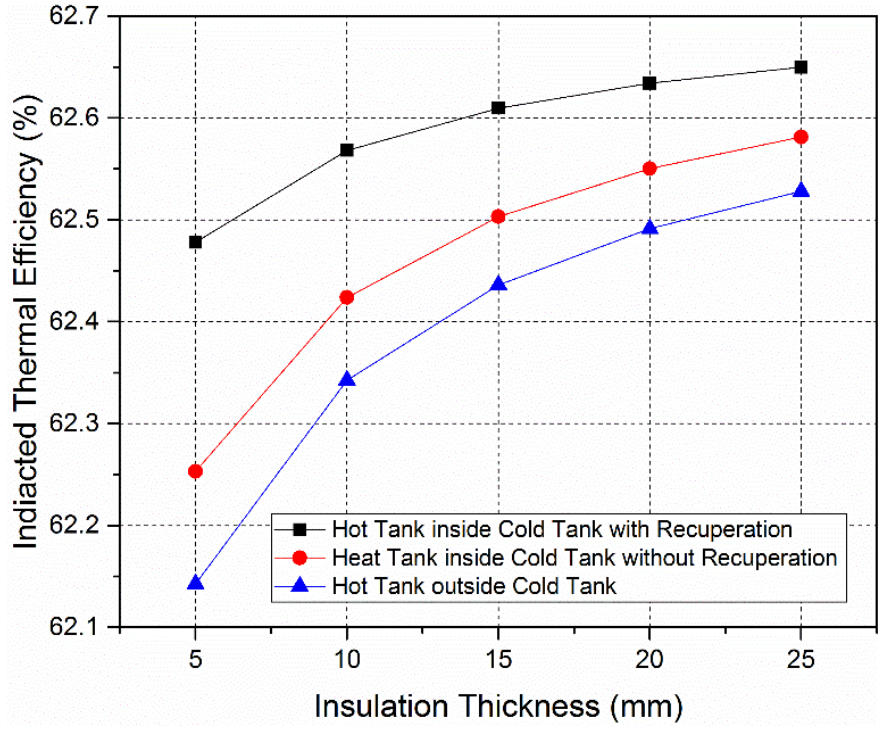

Figure13. ITE with different hot tank insulation thickness and placement. The presence of hot tank inside the cold tank with recuperation reduces the amount of insulation needed.

\section{Influence of Expander Inlet Valve Lift Profile}

The effect on the expander filling on ITE and power split between the high-pressure units and the expander was presented in an earlier section. The influence of the expander valve lift profile is evaluated more systematically in this section. The opening of the inlet valve follows the same profile in all the cases while the maximum lift and ramp on the valve return were varied.

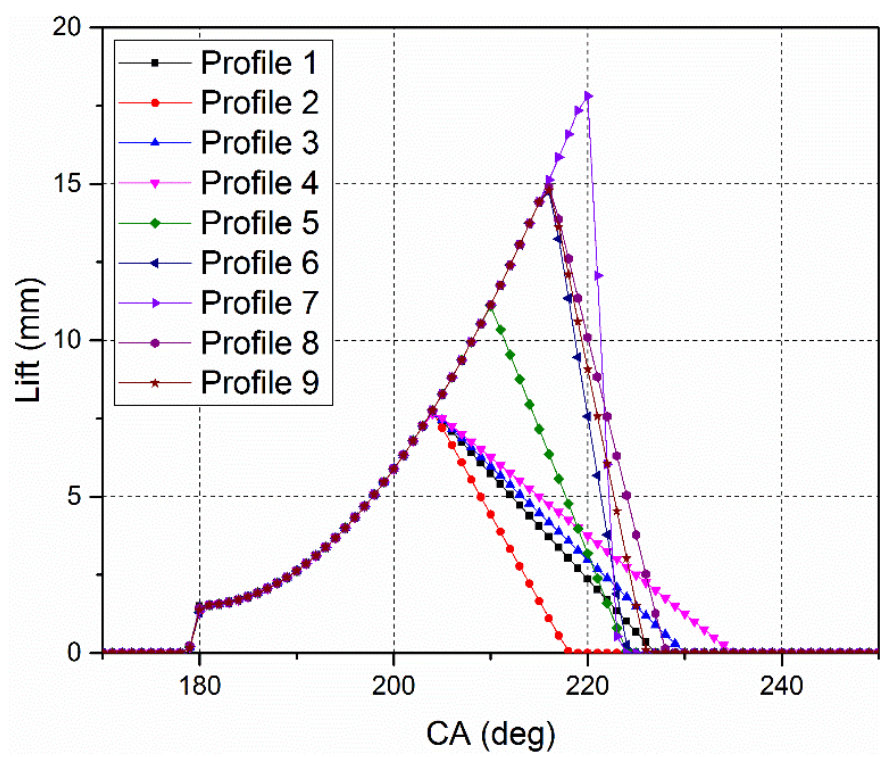

Figure14. Valve profiles for expander inlet. The profiles were created to parameterize different maximum valve lift and closing ramps.

The different valve profiles are presented in Figure 14. Profiles 1, 2, 3 and 4 have the same maximum valve lift but different closing ramps. Profiles 6, 8 and 9 have the same maximum lift with different closing ramps. Profile 5 has similar swallowing capacity as profile 1 but with higher maximum lift and faster closing ramp. Profile 7 has a similar

Page 6 of 9 
relationship with profile 6 . The ITE and hot tank pressure for the various lift profiles are presented in Figure 15. The ITE increases and then decreases with reduction in hot tank pressure as a result of the trade-off between lower pressure acting on the expander piston versus the reduced back-pressure on the high-pressure unit piston. The ITE increases for the same hot tank pressure with increasing maximum valve lift and faster closing ramp due to the increased flow loss across the valve for a slower closing ramp of the valve. The velocities of the gas flow over the valves as well as pressure difference across the valves for profiles 4 and 8 which have the same hot tank pressure are exhibited in Figure 16. The IMEPnet of the high-pressure cylinder units are identical for both profiles but the difference in IMEPnet of the expander is about 0.1 bar which translates to $0.8 \%$ in ITE.

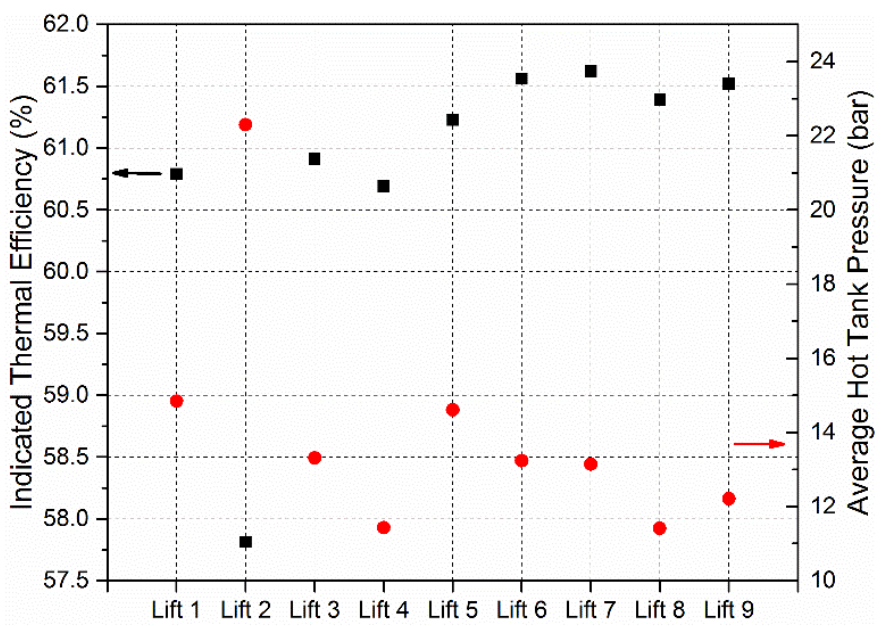

Figure 15. Hot tank pressures and ITE with different valve profiles. The tradeoff between back pressure and ITE is presented.

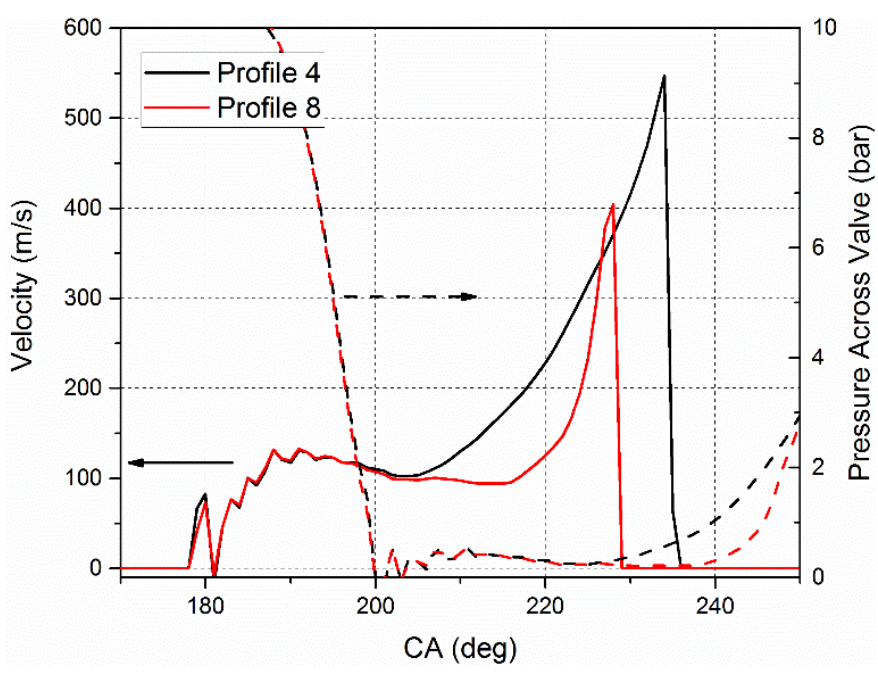

Figure16. Velocity over the valve and the pressure differential across the valve. A faster closing reduces throttling losses over the valve.

\section{Conclusions}

1. A parametric study was conducted to assess the potential of different technologies to improve the efficiency of a configuration of Double Compression Expansion Engine (DCEE).

2. The influence of piston insulation and convection heat multiplier in the high-pressure cylinders, expander head insulation, piping insulation, hot tank insulation, and expander inlet valve timing were simulated using GT power simulations.

3. Lowering the convection heat multiplier (CHM) to values previously calibrated for low-temperature combustion concepts (0.5) provided more significant improvement in indicated thermal efficiency (ITE) compared to using a near adiabatic piston. The effect of insulation on the combustion process was not considered in this study.

4. Insulating the expander head to near adiabatic levels $(1 \mathrm{~W} / \mathrm{m}-\mathrm{K})$ showed an ITE improvement of $0.5 \%$ in all conditions evaluated.

5. The enhanced level of insulation decreased heat transfer losses but as expected increased exhaust losses.

6. The use of a larger expander to utilize a more significant amount of energy flowing into the expander due to insulation did not yield higher efficiencies even for the highest levels of insulation.

7. The addition of insulation thickness in the pipes did not substantially influence ITE after $5 \mathrm{~mm}$.

8. The hot tank insulation could be substainally reduced if it placed inside the cold tank or conversely with greater insulation thickness, the hot tank could be independent of the cold tank.

9. The expander filling and expander inlet valve profile have a significant influence on ITE. The reduction in hot tank pressure due to increased consumption by the expander improves efficiency up to a point.

10. This effect on the ITE is due to a trade-off between pressure acting on the expander and the back-pressure acting on the highpressure units. A larger tank pressure increases expander work but increases pumping work as well as heat loss on the high-pressure units.

11. The ITE also improves for the same hot tank pressure if the maximum valve lift is greater and the valve closing ramp is faster due to reduced flow loss over the valves.

\section{References}

1. Delgado, O. and Lutsey, N., "The U.S. SuperTruck Program," Washington DC, 2014.

2. Lam, N., Tuner, M., Tunestal, P., Andersson, A., Lundgren, S., and Johansson, B., "Double Compression Expansion Engine Concepts: A Path to High Efficiency," SAE Int. J. Engines 8(4):2015-01-1260, 2015, doi:10.4271/2015-011260 .

Page 7 of 9 
3. Bhavani Shankar, V.S., Lam, N., Andersson, A., and

Johansson, B., "Optimum Heat Release Rates for a Double Compression Expansion (DCEE) Engine," 2017, doi:10.4271/2017-01-0636.

4. Gingrich, E., Ghandhi, J., and Reitz, R.D., "Experimental Investigation of Piston Heat Transfer in a Light Duty Engine Under Conventional Diesel, Homogeneous Charge Compression Ignition, and Reactivity Controlled Compression Ignition Combustion Regimes," SAE Int. J. Engines 7(1):2014-01-1182, 2014, doi:10.4271/2014-011182.

5. Jones, J., "Heat Losses in Conventional- and Insulated Exhaust Ports," Lund University, 2015.

6. Jaichandar, S. and Tamilporai, P., "Low Heat Rejection Engines - An Overview," SAE Technical Paper, ISBN 0768013194: 1-17, 2003, doi:10.4271/2003-01-0405.

7. Woschni, G., Spindler, W., and Kolesa, K., "Heat Insulation of Combustion Chamber Walls - A Measure to Decrease the Fuel Consumption of I.C. Engines?," 1987, doi: $10.4271 / 870339$.

8. Alkidas, A.C., "Performance and Emissions Achievements with an Uncooled Heavy-Duty, Single-Cylinder Diesel Engine," 1989, doi:10.4271/890144.

9. No, S.H., Kobiri, S., Kamimoto, T., and Enomoto, Y., "High-Temperature Diesel Combustion in a Rapid Compression-Expansion Machine," 1991, doi:10.4271/911845.

10. Uchida, N. and Osada, H., “A New Piston Insulation Concept for Heavy-Duty Diesel Engines to Reduce Heat Loss from the Wall," SAE Int. J. Engines, 2017, doi:10.4271/2017-24-0161.

11. Tuner, M., Johansson, B., Keller, P., and Becker, M., "Loss Analysis of a HD-PPC Engine with Two-Stage Turbocharging Operating in the European Stationary Cycle," SAE Pap. 2013-01-27, 2013, doi:10.4271/2013-01-2700.

12. Chuahy, F.D.F. and Kokjohn, S.L., "High efficiency dualfuel combustion through thermochemical recovery and diesel reforming," Appl. Energy, 2017, doi:10.1016/j.apenergy.2017.03.078.

13. Manente, V., Zander, C.-G., Johansson, B., Tunestal, P., and Cannella, W., "An Advanced Internal Combustion Engine Concept for Low Emissions and High Efficiency from Idle to Max Load Using Gasoline Partially Premixed Combustion," 2010, doi:10.4271/2010-01-2198.

\section{Contact Information}

Vijai Shankar Bhavani Shankar

Building 5, Level 4,

King Abdullah University of Science and Technology, Thuwal Kingdom of Saudi Arabia

Page 8 of 9

$10 / 19 / 2016$ 
Page 9 of 9

10/19/2016 